\title{
Intersectoral partnership: a potential legacy success of the London 2012 Olympic and Paralympic Games
}

\begin{abstract}
:
The 2008 Legacy Action Plan stated the government's intention to make the United Kingdom (UK) a 'world-leading sporting nation' by using the London 2012 Olympic and Paralympic Games to inspire population changes in physical activity. It set a goal of encouraging two million more people to be active, and responsibility for achieving the target was divided between the sport and health sectors. However, data from the Active People Survey do not confirm a 'legacy effect' on participation as a result of the Games. Despite failure to achieve the target, the Legacy Action Plan was the first UK policy to set a shared national goal for the health and sport sectors and since its publication, the agendas of the two sectors have become increasingly aligned. This presents an unprecedented opportunity for the two sectors to work collaboratively towards the common goal of improving population health through physical activity. It is possible that this coalescence, if maintained, has the potential to create a more sustained legacy on physical activity than may have resulted from the shortlived "inspiration effect" of hosting the London Olympic and Paralympic Games. Rather than dwelling on the 'failure' of the Olympics to achieve the legacy target, efforts should focus on the policy congruence that has developed since the Games, and how to maximise partnership working to achieve a sustained shift in population levels of physical activity.
\end{abstract}

Keywords: sport, health, partnership, collaboration, Olympic, legacy 


\section{Introduction}

Regular physical activity is associated with a reduced risk of many noncommunicable diseases (NCDs) including heart disease, stroke, diabetes, and breast and colon cancer (World Health Organization 2010). It also contributes to the prevention of other important NCD risk factors such as hypertension, overweight and obesity (Physical Activity Guidelines Advisory Committee 2018, World Health Organization 2010). In addition to the physical health benefits, being regularly active is associated with improved mental health (Mammen and Faulkner 2013, Schuch et al. 2016), a delay in the onset of dementia (Livingston et al. 2017), and improved well-being (Das and Horton 2012). Despite these wide ranging benefits however, many adults in the United Kingdom (UK) and globally are insufficiently active (Hallal et al. 2012, Sallis et al. 2016, World Health Organization 2014).

The Global Action Plan on Physical Activity, which was adopted at the World Health Assembly in May 2018, reinforced the importance of national policy responses to address the 'upstream' determinants of physical activity (World Health Organization 2018). This document emphasised the importance of establishing strategic connections between key government departments, stakeholders and related policy priorities to enable sustained implementation at national and subnational levels. While many sectors have a role to play in physical activity promotion (including schools, workplaces, transport and urban planning), there has been a long standing focus on the roles of sport and health, given the clear alignment of these sectors to the physical activity agenda.

The aim of this paper is to explore developments in sport and health policy in England since the announcement of the London 2012 Olympic and Paralympic Games. Specific objectives were: to examine how the London Games changed the context of physical activity and health policy in England; and to explore how changes in policy have influenced implementation of actions aimed at increasing population levels of physical activity. 


\section{The London Games and its impact on national policy}

On $6^{\text {th }}$ July 2005 it was announced that London would host the 2012 Olympic and Paralympic Games. This provided the impetus for the development of national policy that focused on how the Olympics could be used as a platform to promote physical activity to the general public. The Department for Culture, Media and Sport (DCMS) subsequently released Before, During and After: Making the Most of the London 2012 Games (Department for Culture Media and Sport 2008), which stated the government's intention to make the UK a 'world-leading sporting nation'. A key objective set out in this document (colloquially known as the Legacy Action Plan) was to get two million more people 'active' by 2012. 'Active' was defined as participating in sport or physical activity once per week, and the goal equated to around a $13 \%$ increase in the proportion of the population reaching this level of activity over the successive four years. Responsibility for achieving the target was divided between the two lead agencies; Sport England was responsible for initiatives to help one million more people become active through sport, and the Department of Health was charged with helping one million more people become active through participation in a broader range of physical activities (Sport England 2009b).

There had been previous attempts to use the Olympic Games as a vehicle for encouraging population level changes in physical activity. However, previous Games had typically focused on providing public use of Olympic sporting facilities after the Games (Veal et al. 2012). Previous Games had failed to raise sport participation in the host community (Bauman et al. 2015, Craig and Bauman 2014, Weed et al. 2009), indicating either that utilising the Olympics to promote grassroots participation is based on flawed logic (Grix et al. 2017), or that a more comprehensive strategy is required to achieve success. The London hosts took an optimistic view that the Games could be effectively leveraged to 
encourage mass participation if this was embedded in the planning from the outset, and if appropriate resourcing was allocated to infrastructure and programmes to support behaviour change (Bauman and Kamada 2015, Bauman et al. 2013, Weed et al. 2012). However, little evidence was available to guide the approach that was taken; partly because the legacy strategies of previous Games had been limited in scope (e.g facility usage) and partly because previous evaluations had focused on outcomes only, as opposed to understanding the assets of the Games which can be leveraged, and how to maximise opportunities and resourcing (Veal et al. 2012). Before, During and After outlined several key initiatives that might lead to the desired goal, including a healthy living marketing campaign and investment in quality community sport (Department for Culture Media and Sport 2008).

\section{The impact of the London Olympics on population prevalence of physical activity}

Data from the Active People Survey (the primary surveillance system for sport and physical activity throughout the lead up to the Olympics and beyond) do not confirm a 'legacy effect' as a result of the Games. Between the 2007/2008 survey (the year the target was set) and the 2011/2012 survey (the year of the London Olympics), there was an increase in the number of people participating in sport or physical activity once per week of just over 700,000 - well short of the two million target (Sport England 2009a 2012). It could be argued that getting 700,000 people more active is an achievement, despite falling short of the target. However, as the denominator (the total adult population) also increased during this period, it is essential to consider the relative proportion of the population who were active rather than the absolute number. Proportionally $36.6 \%$ of the population were defined as 'active' in $2007 / 2008$, and this increased to $36.9 \%$ in $2011 / 2012$, demonstrating a very small increase in the population prevalence of physical activity. It should be noted that this small increase was not sustained and data from the 2015/2016 survey indicated a fall in prevalence to $36.1 \%$. 
Future policy should focus on setting proportional population targets for achieving recommended physical activity levels, to avoid the pitfall of population growth implying apparent policy success.

\section{The relationship between the sport and health sectors}

Prior to the publication of the Legacy Action Plan in 2008, sport policy had been characterised in two ways; Sport for All (focused on the benefits of sport for society, for example through social values and inclusion) and 'sport for sport's sake' (focused on the number of people regularly taking part in sport, and raising the profile of sport through achieving excellence in competition) (Collins 2010). Policies related to physical activity and health among the general population had traditionally been considered separate and were usually led by the health sector. Only one previous strategy ('Game Plan’2002) had attempted to address both sport and physical activity collectively (Department for Culture Media and Sport Strategy Unit 2002). While this strategy outlined an intention "to encourage a mass participation culture (with as much emphasis on physical activity as competitive sport)" the rhetoric was dominated by the need to enhance international success, particularly in popular sports, and adopting a different approach to hosting sports mega- events (Department for Culture Media and Sport Strategy Unit 2002). According to Game Plan mega-events should "be seen as an occasional celebration of success rather than as a means to achieving other government objectives" (Department for Culture Media and Sport Strategy Unit 2002). Therefore, combining the sport and health agendas within the Legacy Action Plan and setting a collective goal to get two million more people 'active' marked a radical departure from previous policy in terms of addressing both sport and health within the same strategy, and using the Games to contribute to wider public health agendas. 
Collaborative partnership arrangements aimed at achieving common goals are thought to lead to: more effective, equitable, and democratic decision-making; an increase in the quality of provision of services; and better value for money (Balloch and Taylor 2001). However, working in partnership can present challenges when the organisations involved have different values or objectives (Mansfield 2016). Given the relevant agencies had previously worked independently to promote 'health' and 'sport', it was not clear how implementation of the Legacy Action Plan would be operationalised and whether it would enhance or inhibit each sector's efforts to promote physical activity.

\section{Sport and health policy following the Olympics}

The Legacy Action Plan seems to mark the start of greater collaboration between the sport and health sectors to promote physical activity. Since the Olympic Games themselves, there have been major developments in sport and health policy in England, and the agendas of the two sectors appear to have become increasingly aligned. This was most evident in the recent sport strategy, Sporting Future - A New Strategy for an Active Nation (HM Government 2015). Whereas the success of sports policy in England had traditionally been measured by participation figures, the new approach focused on demonstrating the impact of sport on five key outcomes: physical wellbeing; mental wellbeing; individual development; social and community development; and economic development. This shift in focus appears to be driven by an increased mandate from policymakers for the sport sector to demonstrate the contribution that sport can make to public health, which might be traced back to a Sport England commissioned review of the evidence in 2012 (Cavill et al. 2012). Whilst redefining success to focus on a range of health-related outcomes is a positive development for the physical activity and health agenda, these indicators are challenging to measure, and thus there is limited evidence on the potential contribution that physical activity and sport could 
make. Further, due to uncertainty around how to measure these broad outcomes, it will be challenging to monitor and evaluate the success of the new strategy. This adds a further complication to the already challenging nature of evaluation, which stems from the limited capacity, resources, and evaluation expertise among grassroots delivery organisations (Katikireddi et al. 2011).

Sport England is the lead agency responsible for delivering on the Sporting Future policy and has released an accompanying implementation plan, Towards an Active Nation (Sport England 2016). This document includes a specific focus on targeting the inactive and providing sport and physical activity opportunities for all. In addition, whereas sport policy had traditionally centred on a strict definition of sport (as opposed to broader physical activity), the new strategy supports a wide range of non-sports activities including walking. This is a significant public-health development: walking has often been debated in policy discussions, with public health agencies seeing it as the single physical activity with the greatest potential to improve public health, but sports agencies insisting that they could not promote something that was not defined as 'sport'(Milton and Grix 2015).

In 2013, Public Health England was established as an executive agency of the Department of Health, and has since taken over responsibility for much of the physical activity agenda from a health perspective. The new sports strategy aligns well with the current Public Health England strategy, Everybody Active Every Day (Public Health England 2014) and many of the actions set out within the new Sport England strategy are explicitly to be undertaken in collaboration with Public Health England. In May 2017, Public Health England appointed a new Physical Activity Programme Manager. This new employee spends one day per week based at Sport England, to strengthen relationships and communication between the two agencies and reinforce a sense of shared ownership and responsibility for the physical activity and health agenda. 
The focus on a combined sport and health strategy has survived two changes in political leadership since the Legacy Action Plan was published (in 2010 and 2015), suggesting that this new collaborative approach could mark a sustained 'legacy' effect of the 2012 Games. Furthermore, an inter-ministerial group on healthy living has recently been established, focused on promoting healthy living for all to help reduce inequalities in health, with a specific focus on sport and physical activity. A key focus of this group is to establish cross-sector actions for achievement of the five key outcomes in the sport strategy. The group is co-chaired by the Secretary of State for Digital, Culture, Media and Sport and the Secretary of State for Health and Social Care. Members includes the chief executive of Sport England and the Chief Medical Officer.

To ensure this new strategy direction translates into real changes in physical activity and health at the population level, engagement and cooperation will be required at all levels down to grassroots delivery, and there are already examples of this happening in practice. For example, Sport England recently invested $£ 130$ million in 10 local pilot schemes designed to tackle inequalities in activity levels over the next four years; these pilots are almost entirely focused on a broad definition of physical activity and aim to take a 'systems' approach rather than working only through sports channels. For example, the largest funded programme in Greater Manchester states that 'we will lead policy, legislation and systems change to support active lives, ensuring that physical activity becomes a central feature in policy and practice related to planning, transport, health and social care, economics, education and the environment (Greater Sport 2018). Similarly, the Sport England-funded 'Gloucestershire Moves' programme states it 'is a "whole system approach" to raise physical activity levels across the county and get everyone in Gloucestershire moving' (Active Gloucestershire 2018). 
It is critical that robust programme evaluation is in place to monitor the implementation and success of the new strategy. This will require appropriate evaluation methods, and must be supported by clear guidance on how to measure each of the five key outcomes in the new strategy. Furthermore, consistent surveillance through the Active Lives Survey (which replaced the Active People Survey in 2017) will provide evidence on the effectiveness of the new policy approach in influencing population levels of physical activity.

\section{Conclusions}

The recent alignment of the sport and health agendas to tackle physical inactivity presents an unprecedented opportunity for the two sectors to work collaboratively towards the common goal of improving population health through physical activity. It is possible that this coalescence has the potential to create a larger and more sustained legacy effect than may have resulted from the short-lived "inspiration effect" of hosting the London Olympic and Paralympic Games. Rather than dwelling on the 'failure' of the Olympics to achieve a shift in population prevalence of physical activity, efforts should focus on the policy congruence that has emanated since the Games, and how to maximise partnership working to achieve a sustained shift in population physical activity. Whilst the nascent policy partnership between sport and health is encouraging, experience from other countries shows that it is only likely to make a detectable difference if it can be sustained in the long term.

\section{References}

Active Gloucestershire, 2018. Gloucestershire Moves. Available from: https://www.activegloucestershire.org/events-and-campaigns/gloucestershire-moves.php [Accessed 29 May 2018].

Balloch, S., and Taylor, M., 2001. Partnership working: policy and practice. Bristol: Policy 
Press.

Bauman, A., Bellew, B., and Craig, C., 2015. Did the 2000 Sydney Olympics increase physical activity among adult Australians? British Journal of Sports Medicine, 49(4), $243-247$.

Bauman, A., and Kamada, M., 2015. The potential effects of the Tokyo 2020 Olympic and Paralympic Games on physical activity participation at the population level. Research in Exercise Epidemiology, 17(2), 75-80.

Bauman, A., Murphy, N., and Matsudo, V., 2013. Is a population-level physical activity legacy of the London 2012 Olympics likely? Journal of Physical Activity and Health, $10,1-4$.

Cavill, N., Richardson, D., and Foster, C., 2012. Improving health through participation in sport: a review of research and practice. Oxford, UK.

Collins, M., 2010. From “sport for good” to “sport for sport"s sake' - not a good move for sports development in England? International Journal of Sport Policy, 2(3), 367-379.

Craig, C., and Bauman, A., 2014. The impact of the Vancouver Winter Olympics on population level physical activity and sport participation among Canadian children and adolescents: population based study. International Journal of Behavioral Nutrition and Physical Activity, 11(1), 107.

Das, P., and Horton, R., 2012. Rethinking our approach to physical activity. The Lancet, 380(9838), 189-190.

Department for Culture Media and Sport, 2008. Before, during and after: Making the most of the London 2012 Games. London: Department for Culture Media and Sport.

Department for Culture Media and Sport Strategy Unit, 2002. Game plan: A strategy for delivering government's sport and physical activity objectives. London: Department for Culture Media and Sport. 
Greater Sport, 2018. Policy and strategic architecture. Available from:

https://www.greatersport.co.uk/get-active/aims/ambition-13e [Accessed 29 May 2018].

Grix, J., et al., 2017. State strategies for leveraging sports mega-events: unpacking the concept of "legacy." International Journal of Sport Policy and Politics, 9(2), 203-218.

Hallal, P., et al., 2012. Global physical activity levels: Surveillance progress, pitfalls, and prospects. Lancet, 380, 247-257.

HM Government, 2015. Sporting Future: A New Strategy for an Active Nation. London: HM Government.

Katikireddi, S., et al., 2011. How evidence based is English public health policy? British Medical Journal, 343, d7310.

Livingston, G., et al., (2017). Dementia prevention, intervention, and care. The Lancet, 390(10113), 2673-2734.

Mammen, G., and Faulkner, G., 2013. Physical activity and the prevention of depression: A systematic review of prospective studies. American Journal of Preventive Medicine, 45(5), 649-657.

Mansfield, L., 2016. Resourcefulness, reciprocity and reflexivity: the three Rs of partnership in sport for public health research. International Journal of Sport Policy and Politics, 8(4), 713-729.

Milton, K., and Grix, J., 2015. Public health policy and walking in England - analysis of the 2008 “policy window”. BMC Public Health, 15(1), 614.

Physical Activity Guidelines Advisory Committee, 2018. 2018 Physical Activity Guidelines Advisory Committee Scientific Report. Washington, DC, USA: Department of Health and Human Services.

Public Health England, 2014. Everybody active, every day - An evidence-based approach to physical activity. London: Public Health England. 
Sallis, J., et al., 2016. Progress in physical activity over the Olympic quadrennium. The Lancet, 24(388), 1325-1336.

Schuch, F., et al., 2016. Exercise as a treatment for depression: A meta-analysis adjusting for publication bias. Journal of Psychiatric Research, 77, 42-51.

Sport England, 2009a. Active People Survey 2007/08: Individual Sports Participation. London: Sport England.

Sport England, 2009b. Briefing Note: Explanation of the different sport participation indicators. London: Sport England.

Sport England, 2012. Active People Survey 6. London: Sport England.

Sport England, 2016. Sport England: Towards an active nation. Strategy 2016-2021. London: Sport England.

Veal, A., Toohey, K., and Frawley, S., 2012. The sport participaton legacy of the Sydney 2000 Olympic Games and other international sporting events hosted in Australia. Journal of Policy Research in Tourism, Leisure and Events, 4(2), 155-184.

Weed, M., Coren, E., and Fiore, J., 2009. A systematic review of the evidence base for developing a physical activity and health legacy from the London 2012 Olympic and Paralympic Games. Canterbury, UK: Canterbury Christ Church University.

Weed, M., et al., 2012. Developing a physical activity legacy from the London 2012 Olympic and Paralympic Games: a policy-led systematic review. Perspectives in Public Health., 132(2), 75-80.

World Health Organization, 2010. Global recommendations on physical activity for health. Geneva, Switzerand: World Health Organization.

World Health Organization, 2014. Global status report on noncommunicable diseases 2014. Geneva, Switzerland: World Health Organization.

World Health Organization, 2018. Global Action Plan on Physical Activity 2018 - 2030 - 
More active people for a healthier world. Geneva, Switzerland: World Health Organization. 